\title{
Comparative study of GC-MS characterization, antioxidant activity and hyaluronidase inhibition of different species of Lavandula and Thymus essential oils
}

\author{
Alejandro Carrasco, ${ }^{a *}$ Virginia Tomas, ${ }^{b}$ Jose Tudela $^{a}$ and Maria G. Miguel ${ }^{c}$
}

\begin{abstract}
The chemical compositions of essential oils of Lavandula angustifolia, Lavandula latifolia, Lavandula hybrida cultivar Grosso and cultivar Super, Thymus zygis with high proportions of thymol and linalool and Thymus hyemalis, from Murcia country (Spain), were studied in relative (\%), absolute ( $\mathrm{mM}$ ) and chiral concentrations by GC/MS. Hyaluronidase inhibition and antioxidant activities of the essential oils were evaluated using ABTS ${ }^{+}$, DPPH', ORAC, chelating power, hydroxyl radical, nitric oxide, TBARS and reducing power assays. Linalool and linalyl acetate were the most abundant components in the Lavandula genus whereas thymol, linalool and 1,8-cineole were the most abundant molecules in the respective Thymus species. Chiral determination of the main components showed (+)-enantiomers like terpinen-4-ol, $\beta$-pinene, borneol and $\alpha$-terpineol and $(-)$-enantiomers like linalool, linalyl acetate and camphene in Lavandula sp. In the case of Thymus sp. (+)-enantiomers like $\alpha$-pinene, limonene, terpinen-4-ol and $\alpha$-terpineol and (-)-enantiomers like borneol were found. Essential oils containing thymol were found especially powerful in all assays but chelating power, ORAC and hydroxyl radical scavenging assays. The capacity for inhibiting hyaluronidase showed that $T$. zygis with a high proportion of thymol was the most effective inhibitor. Essential oils containing thymol and linalool/linalyl acetate have a potential use as antioxidant agents. Thymol shows strong inhibition of hyaluronidase. Copyright $\odot 2015$ John Wiley \& Sons, Ltd.
\end{abstract}

Keywords: lavandula; thymus; antioxidant; hyaluronidase inhibition; essential oil

\section{Introduction}

The genus Lavandula belongs to the Lamiaceae family and includes 39 known species. However, there are three important species because of their terpenoid-rich essential oils (EOs), which are obtained by steam distillation. They are L. angustifolia Mill. (L. officinalis Chaix ex. Vill, L. spica L, L. vera DC) or true lavender; L. latifolia Medik. or spike lavender; and the natural hybrid L. $x$ intermedia Emeric ex Loisel (L. hybrida L.) or lavandin that is derived from a cross of $L$. latifolia $\times L$. angustifolia. EOs are extensively used in perfumes, in cosmetics, in food manufacturing for flavouring beverages, ice creams, candies, baked goods and chewing gums, and in aromatherapy as relaxants. ${ }^{[1,2]}$

Lavandula angustifolia is one of the most desired lavender oils in the cosmetic and aromatherapeutic industries, which is as a result of the high concentration of both linalool/linalyl acetate and lowcamphor concentration. However, true lavender produces this interesting EO in relatively low amounts. For the higher production of this EO, hot, dry climates and medium altitudes (700-1200 m) are required. ${ }^{[3]}$ The yield of EO from lavandin is three-fold higher than the one of $L$. angustifolia, albeit with much lower application in perfumery and therapy owing to the undesirably high levels of camphor. Such oil is preferentially used as the antiseptic, antifungal and antibacterial agent. ${ }^{[3]}$ These biological properties have also been attributed to $L$. angustifolia and L. latifolia. In addition, they have also been used as sedative, carminative, anti-depressive and anti-inflammatory agents, although clinical studies show inconclusive results. ${ }^{[4]}$ Lavandula latifolia is also believed to be effective for burns and insect bites. ${ }^{[5]}$
The genus Thymus is one of the eight most important genera regarding the number of species included: more than 300 , including hybrids, varieties and ecotypes. ${ }^{[6]}$

Thymus hyemalis Lange, winter thyme, can be found mainly in the South East of Spain (Alicante, Murcia and Almeria). ${ }^{[7]}$ Chemical variability has been reported for the essential oils of this species, the presence of at least four chemotypes in that region of Spain was stated beyond the seasonal variations and edaphic and climatic conditions. ${ }^{[7,8]}$

The antimicrobial activity of $T$. hyemalis EO was found in $2008{ }^{[9]}$ being thymol chemotype more active than carvacrol chemotype. The antimicrobial activity along with antioxidant activity of winter thyme EO were also reported. ${ }^{[10]}$

Thymus zygis Loefl. ex L. is a widespread endemic plant in the Iberian Peninsula. At least eight chemotypes have been found in

\footnotetext{
* Correspondence to: Alejandro Carrasco Ruiz, Department of Biochemistry and Molecular Biology-A, Faculty of Veterinary Science, University of Murcia, Campus of Espinardo, 30100, Murcia, Spain. E-mail: alejandro.carrasco@um.es

a GENZ-Group of research on Enzymology, Department of Biochemistry and Molecular Biology-A, Regional Campus of International Excellence 'Campus Mare Nostrum;, University of Murcia, Murcia, Spain

b Department of Analytical Chemistry, University of Murcia, Murcia, Spain

c University of Algarve, Centre for Mediterranean Bioresources and Food, Faculty of Sciences and Technology, Department of Chemistry and Pharmacy, Building 8, Campus de Gambelas, 8005-139, Faro, Portugal
} 
this region. ${ }^{[11]}$ Seasonal variations and phenological stages are also factors that contribute to the chemical variability of T. zygis EOs. ${ }^{[12]}$

Antimicrobial, antigiardial, antiviral, anti-enzymatic and antioxidant activities of $T$. zygis EOs have been reported. ${ }^{[10,13-18]}$

Gas chromatography (GC), coupled with mass spectrometry detection, is a powerful technique used for volatile components analysis, as it provides qualitative and quantitative data for complex mixtures such as those usually present in EOs. ${ }^{[19]}$

The quantitative composition of EOs may be estimated using relative percentage abundance, internal standard normalized percentage abundance and true quantitation of one or more compounds by a validated method. ${ }^{[20]}$ So far, relative percentage abundance is the most commonly method used in the EO analysis. However, it should only be used to measure relative component ratios in a single sample and not to compare compositions of a group of EOs, because relative percentage abundances are not standardized. ${ }^{[20]}$

Furthermore, there are scarce chiral studies accounting for the main components of the studied EOs. Observing the enantiomeric distribution of the main molecules of the EOs is highly interesting, as different bioactivities and organoleptic properties depend on the enantiomeric ratios. These characteristics are useful in the formulation and authenticity assessment of drugs, fragrances and flavours. $^{[1,21]}$

The antioxidant activities of the mentioned EOs have been found to be interesting because oxidation, induced by reactive oxygen and nitrogen species (ROS and RNS), can damage membranes, lipids and lipoproteins and can induce DNA mutation. These types of cell or tissue injuries have been associated with ageing, atherosclerosis, carcinogenesis and cardiovascular as well as Alzheimer's and other neurological diseases. Thus, preventing or minimizing these oxidation processes, by the use of antioxidant substances that scavenge hydroxyl $\left(\mathrm{HO}^{\circ}\right)$, nitric oxide $\left(\mathrm{NO}^{*}\right)$ or other free radicals, may help in the treatment of the aforementioned illnesses. ${ }^{[1,4,6,22-24]}$

The extracellular matrix (ECM) breakdown is related with oxidative stress and degradation of proteins such as collagen and elastin. It is also related to hydrolysis, catalyzed by hyaluronidase, of proteoglycans with glycosaminoglycans such as hyaluronic acid. Hyaluronic acid is a polysaccharide composed of D-glucuronic acid and D-Nacetylglucosamine, linked via alternating $\beta-1,4$ and $\beta-1,3$ glycosidic bonds, with a size from $5000 \mathrm{Da}$ to $20 \mathrm{MDa}$ in vivo. Hyaluronic acid imbibes water, provides resilience to cartilages, replaces fibres of degraded collagen and enhances the regeneration of collagen by the dermis and the ECM. The hyaluronic acid/hyaluronidase system also participates in many pathophysiological conditions such as envenomation, acrosome reaction/ovum fertilization, microbial pathogenesis and cancer progression. The inhibitors of hyaluronidase might serve as a contraceptive, anti-venom/toxin, anti-microbial, antiaging, anti-inflammatory and anticancer agents. ${ }^{[25]}$

The aim of this study was to determine thoroughly the chemical composition and bioactivities of the EOs of four species of Lavandula genus (Lavandula angustifolia, Lavandula latifolia, Lavandula hybrida cultivar Grosso and cultivar Super) and three of Thymus genus (two samples of Thymus zygis and one sample Thymus hyemalis). Source plants were grown under organic farming in the Murcia country (Spain). Their relative and absolute concentrations, as well as the proportions of their main chiral compounds, will be determined. Also, several antioxidant methods will evaluate the antioxidant capacity of EOs against different oxidant agents. Furthermore, the potential bioactivity of EOs on the important and multifunctional hyaluronic acid/hyaluronidase system will be determined. Thus, this study is focused on increasing the diversity of available compositions and bioactivities of these EOs with samples from Murcia and comparing them with EOs from different parts of the world. Hence, this study aims to broaden the knowledge about composition, antioxidant and anti-hyaluronidase properties of Lavandula and Thymus EOs.

\section{Materials and methods}

\section{Plant material and extraction}

Seven samples (300 g each) of L. angustifolia, L. latifolia, L. hybrida cultivar Grosso, L. hybrida cultivar Super, T. zygis with a high proportion of thymol, T. zygis with a high proportion of linalool and T. hyemalis (with identification numbers of the voucher specimens BMBA130901, BMBA130902, BMBA130903, BMBA130904, BMBA130905, BMBA130906 and BMBA130907, respectively) were obtained from organic farming fields dedicated to growing plants for industrial extraction of EOs through steam distillation, located in 'Region de Murcia', a country of the South East of Spain with a rich plant biodiversity. The species were identified and authenticated by Dr Pedro Sanchez-Gomez, Professor of Botany in the Plant Biology department of Murcia University and voucher specimens were prepared and deposited in the herbarium of the Department of Biochemistry and Molecular Biology-A.

The dry plants of each sample were separately subjected to steam distillation for $3 \mathrm{~h}$ with a Clevenger apparatus. The oil collected was dried over anhydrous sodium sulphate, obtaining strong smelling pale yellow oil that was stored at $-20^{\circ} \mathrm{C}$ until used.

\section{Chemicals}

The following compounds were purchased from Sigma-AldrichFluka: pure compounds used as standard substances for GC identification, ABTS, DPPH, AAPH, fluorescein, PBS, 2-deoxyribose, sodium hydroxide, sodium borate, calcium chloride, bovine hyaluronidase, p-dimethylamino benzaldehyde, ferrozine, iron(II) chloride, iron(III) chloride, potassium hexacyanoferrate (II), potassium chloride, sodium dodecyl sulfate, n-butanol, BHT, mannitol, rutin, ascorbic acid. Analytic grade solvents, hydrogen peroxide, thiobarbituric acid and buffers were acquired from Merck. Sodium persulfate, Trolox, sodium hyaluronate and EDTA were acquired from Acros organics. Sodium nitroprusside was purchased from Riedel-deHaen. Griess reagent system kit was obtained from Promega. Trichloroacetic acid was obtained from VWR. Iron (II) sulfate was purchased from Panreac. Deionized laboratory water type I $(18 \mathrm{M} \Omega \cdot \mathrm{cm})$ was produced with a Millipore MilliQ-Reference device.

\section{Fast gas chromatography-electron impact/mass spectrometry (FGC-El/MS)}

FGC-El/MS analyses of the essential oils were conducted using an Agilent GC7890 chromatograph (Agilent Technologies, Santa Clara, CA, USA), coupled with an Agilent MS5975 mass spectrometer as a detector. The analysis was performed on a low bleed capillary fused-silica column, SLB- $5 \mathrm{~ms}$ from Supelco $(15 \mathrm{~m}$ length $\times 0.1 \mathrm{~mm}$ i.d. $\times 0.1 \mu \mathrm{m}$ film thickness). The carrier gas used was hydrogen (flow rate constant: $0.8 \mathrm{ml} / \mathrm{min}$, starting column head pressure: $46.345 \mathrm{psi}$ ), produced ad hoc with an electrolytic ParkerDomnik-Hunter generator, fed with type I laboratory water. The above-mentioned complex device was controlled by ChemStation software and analysed using ChemStation, MS-Search, AMDIS and the mass spectral databases NIST 08 and Wiley 7. The injector 
temperature was held at $280^{\circ} \mathrm{C}$; the septum purge was set to $3 \mathrm{ml} / \mathrm{min}$ and the split valve was set to $100: 1$. The column temperature started at $60^{\circ} \mathrm{C}$ and increased to $300^{\circ} \mathrm{C}$ according to the temperature programme as follows: rate $20^{\circ} \mathrm{C} / \mathrm{min}$ to $142^{\circ} \mathrm{C}$, and rate $40^{\circ} \mathrm{C} / \mathrm{min}$ from $142^{\circ} \mathrm{C}$ to $300^{\circ} \mathrm{C}$ and then held for $0.5 \mathrm{~min}$. MS conditions were as follows: temperature of the transfer line $280^{\circ} \mathrm{C}$, Electron lonization energy $70 \mathrm{eV}$, mass range 30-300 atomic mass units, scan rate $21.035 \mathrm{scan} / \mathrm{s}$. The EO compounds were identified based on retention time, retention index and mass spectra of the pure compounds (standards) compiled in an in-lab built library using MSD Chemstation Data Analysis. Tentative identification, for each component not available commercially, was attempted comparing the retention index and mass spectra against NIST and Wiley spectral databases using NIST MS Search 2.0 (NIST, Gaithersburg, MD, USA). The quantitative determination was carried out based on calibration curves of each of the commercially available components of the essential oils. Those curves were made using nonane (MS 43, 57, 71, 85), tetradecane (MS 43, 57, 71, 85) and hexadecane (MS 41, 43, 57, 71) as internal standards, calibration ranges and suppliers for all substances are listed in Table 1. Calibration curves are expressed as the response ratio $\left(\frac{\text { analyte response }}{\text { internal standard response }}\right)$ vs. the concentration ratio ( $\left.\frac{\text { analyte concentration }}{\text { internal standard concentration }}\right)$, thus, correction factors of each analyte are embedded in the calibration curves. Each sample was evaluated in two different dilutions in isooctane, 1:10 and 1:1000 in order to determine exact concentrations of compounds.

The repeatability of five detections of 3-mM samples is shown in the RSD column for all standards. The limit of detection (LOD) was calculated by a signal-to-noise ratio of 3, and the limit of quantitation (LOQ) was determined by a signal-to-noise ratio of $10 .{ }^{[26]}$

In the case of non-commercially available compounds, the percentage of the peak area of the total ion chromatogram was evaluated. Retention indices (LRIs) were calculated using a homologous series of $C_{7}-C_{30} n$-alkanes standard solutions from Supelco, according to the IUPAC recommendations ${ }^{[27]}$ for linear retention indices.

\section{Enantioselective gas chromatography-electron impact/mass spectrometry (EsGC-EI/MS)}

The same analytical device described above was used, this time equipped with an Astec Chiraldex B-DM column (30 m length $\times$ $0.25 \mathrm{~mm}$ i.d. $x 0.12 \mu \mathrm{m}$ film thickness) from Supelco. Performing under milder conditions, this column provided chiral chromatograms of the essential oils, where the chiral compounds were determined by the retention time of the pure enantiomers commercially available, and double checked with the NIST spectral database. The peak areas of the triplicates were integrated, and enantiomeric ratios of levorotatory $(-)$ and dextrorotatory $(+)$ enantiomers were determined. Conditions: injector temperature $200^{\circ} \mathrm{C}$, transfer line temperature $200^{\circ} \mathrm{C}$, split 100:1, temperature programme as follows: starting at $35^{\circ} \mathrm{C}$, the temperature increased to $170^{\circ} \mathrm{C}$ at a rate of $4{ }^{\circ} \mathrm{C} / \mathrm{min}$, then the temperature decreased to $35^{\circ} \mathrm{C}$ at a rate of $15^{\circ} \mathrm{C} / \mathrm{min}$.

\section{Determination of ABTS radical cation scavenging capacity}

The ABTS [2,2'-azino-bis(3-ethylbenzothiazoline-6-sulphonic acid)] radical cation decolourization assay was carried out using the method already reported in the literature ${ }^{[28]}$ with slight modifications. An ABTS radical cation $\left(\mathrm{ABTS}^{\bullet+}\right.$ ) was produced by reacting $3.5 \mathrm{mM}$ ABTS with $2.45 \mathrm{mM}$ potassium persulfate (final concentration) and keeping the mixture in the dark at room temperature for 12-16 $\mathrm{h}$ before use.

An ethanolic solution $(10 \mu \mathrm{l})$ of the samples at various concentrations $(0-0.5 \mathrm{~g} / \mathrm{l})$ was mixed with $990 \mu \mathrm{l}$ of $0.035 \mathrm{mM} \mathrm{ABTS}^{\bullet+}$ solution. After reaction at room temperature for $6 \mathrm{~min}$, the absorbance at $734 \mathrm{~nm}$ was measured using a Shimadzu 160-UV spectrophotometer (Tokyo, Japan). The ability to scavenge ABTS ${ }^{\bullet+}$ was calculated using the formula given below:

$$
\text { scavenging or inhibitory activity }(\%)=\left[\frac{\left(A_{0}-A_{1}\right)}{A_{0}}\right] \times 100
$$

Where $A_{0}$ is the absorbance of the control and $A_{1}$ is the absorbance in the presence of the sample. Trolox was used as a reference to express the results in TEAC units ( $\mu \mathrm{mol}$ Trolox equivalent / g essential oil).

\section{Free radical scavenging activity (DPPH)}

A methanolic stock solution ( $50 \mu \mathrm{l})$ of each sample at different concentrations was placed in a cuvette, adding $2 \mathrm{ml}$ of $60 \mu \mathrm{M}$ methanolic solution of DPPH (2,2-diphenyl-1-picrylhydrazyl). ${ }^{[29]}$ Absorbance measurements were made at $517 \mathrm{~nm}$, after $60 \mathrm{~min}$ of reaction in the dark, at room temperature. The values of scavenging activity were reported in TEAC units, according to the same process shown in the ABTS assay.

\section{ORAC}

The ORAC values account for the ability of the samples to scavenge the peroxyl radical (ROO).). ORAC values were determined using a slight modification of the reported method. ${ }^{[30]}$

This assay was performed at $37^{\circ} \mathrm{C}$ for $60 \mathrm{~min}$, in a Molecular Devices Gemini XPS fluorometer controlled by the software SoftMaxPro, using a 96-well plate, each well having a filled volume of $300 \mu$ l. Each sample was evaluated in triplicate using $\lambda_{\text {ex }}=485 \mathrm{~nm}$ and $\lambda_{\text {em }}=530 \mathrm{~nm}$. Each assay consisted of pH7.5, $10 \mathrm{mM}$ phosphate buffer, $1 \mu \mathrm{M}$ fluorescein, $200 \mathrm{mM}$ AAPH and an antioxidant sample in several concentrations. The organic solvent was $1 \%$ ethanol for all assays. The values of scavenging activity were reported in TEAC units, according to the same process shown in the ABTS assay.

\section{Chelating power of metallic ions}

The degree of chelation of ferrous ions by essential oils was evaluated according to the literature. ${ }^{[31]}$ Briefly, samples were incubated $1: 1$ with $0.025 \mathrm{ml}$ of $2 \mathrm{mM} \mathrm{FeCl}_{2}$. The addition of $0.025 \mathrm{ml}$ of $5 \mathrm{mM}$ ferrozine initiated the reaction, and after $10 \mathrm{~min}$, the absorbance at $562 \mathrm{~nm}$ was measured. An untreated sample served as the control. The percentage of chelating ability was determined according to Eqn (1). EDTA was used as a positive control.

\section{Hydroxyl radical scavenging activity}

The assay of hydroxyl radical $\left(\mathrm{OH}^{-}\right)$scavenging activity was developed with small modifications to the reported method. ${ }^{[32]}$ Briefly, the reaction mixture was prepared with $10 \mathrm{mM} \mathrm{FeSO}_{4} 7 \mathrm{H}_{2} \mathrm{O}$, $10 \mathrm{mM}$ EDTA, $10 \mathrm{mM}$ 2-deoxyribose, $0.1 \mathrm{M}$ phosphate buffer and sample at different concentrations in a test tube to give a total volume of $1.8 \mathrm{ml}$. Finally, $200 \mu \mathrm{l}$ of $0.1 \%(\mathrm{v} / \mathrm{v}) \mathrm{H}_{2} \mathrm{O}_{2}$ were added to the mixture and incubated at $37^{\circ} \mathrm{C}$ for $4 \mathrm{~h}$. 
Table 1. Standards used in GC/MS and calibration curves for essential oils (EOs) analysis

\begin{tabular}{|c|c|c|c|c|c|c|c|c|}
\hline Analyte & $\begin{array}{c}\text { Calibration } \\
\text { curve }^{a}\end{array}$ & $\mathbf{R}^{2}$ & $\begin{array}{l}\text { Calibration range } \\
\qquad(\mathbf{m M})\end{array}$ & $\begin{array}{r}\text { RSD } \\
(\%)\end{array}$ & $\begin{array}{l}\text { LOD } \\
(\mathrm{mM})\end{array}$ & $\begin{array}{l}\text { LOQ } \\
(\mathrm{mM})\end{array}$ & $\begin{array}{l}\text { Standard } \\
\text { source }\end{array}$ & $\begin{array}{l}\text { Product } \\
\text { Reference }\end{array}$ \\
\hline Nonane & Internal standard & & & & & & SAFC & 442694 \\
\hline$\alpha$-Thujene & $y=0.566 x-0.045$ & 0.997 & $0.50-10.09$ & 6.0 & 0.16 & 0.47 & EML & \\
\hline$(-)$ - $\alpha$-Pinene & $y=0.471 x-0.018$ & 0.997 & $0.25-10.06$ & 4.5 & 0.08 & 0.25 & Fluka & 80599 \\
\hline (+)-Camphene & $y=0.272 x-0.008$ & 0.995 & $0.66-10.51$ & 0.4 & 0.14 & 0.44 & SAFC & w222909 \\
\hline Sabinene & $y=0.460 x-0.026$ & 0.998 & $0.24-9.78$ & 0.9 & 0.07 & 0.21 & Extrasynthese & $5062 \mathrm{~S}$ \\
\hline (-)- $\beta$-Pinene & $y=0.400 x-0.016$ & 0.995 & $0.26-10.29$ & 3.7 & 0.09 & 0.26 & Fluka & 80609 \\
\hline 3-Octanone & $y=0.309 x-0.031$ & 0.996 & $2.56-10.24$ & 4.1 & 0.64 & 1.95 & SAFC & w280305 \\
\hline Myrcene & $y=0.188 x-0.024$ & 0.993 & $2.24-8.97$ & 3.5 & 0.56 & 1.70 & Fluka & 64643 \\
\hline Hexyl acetate & $y=0.452 x-0.057$ & 0.992 & $2.40-9.59$ & 1.7 & 0.32 & 0.96 & Fluka & 25539 \\
\hline$\alpha$-Phellandrene & $y=0.430 x-0.012$ & 0.998 & $0.50-9.52$ & 0.9 & 0.16 & 0.49 & Aldrich & 77429 \\
\hline$\alpha$-Terpinene & $y=0.425 x-0.035$ & 0.997 & $0.45-9.45$ & 2.8 & 0.15 & 0.44 & Aldrich & 86473 \\
\hline p-Cymene & $y=0.830 x-0.020$ & 0.995 & $0.25-9.95$ & 4.9 & 0.02 & 0.05 & Aldrich & c121452 \\
\hline (+)-Limonene & $y=0.246 x-0.008$ & 0.995 & $0.60-9.55$ & 0.9 & 0.12 & 0.36 & Fluka & 62118 \\
\hline (Z)- $\beta$-Ocimene & $y=0.218 x-0.011$ & 0.996 & $0.70-6.97$ & 2.2 & 0.16 & 0.48 & SAFC & w353901 \\
\hline 1,8-Cineole & $y=0.233 x-0.008$ & 0.995 & $2.39-9.55$ & 8.7 & 0.60 & 1.82 & SAFC & w246506 \\
\hline$\gamma$-Terpinene & $y=0.366 x-0.017$ & 0.995 & $0.62-9.87$ & 2.8 & 0.12 & 0.37 & Aldrich & 223190 \\
\hline (+)-trans-Sabinene hydrate & $y=0.268 x-0.007$ & 0.996 & $0.63-10.00$ & 2.1 & 0.18 & 0.56 & Fluka & 96573 \\
\hline$(-)$-Linalool & $y=0.214 x-0.008$ & 0.994 & $0.88-8.80$ & 4.9 & 0.22 & 0.67 & Fluka & 74856 \\
\hline 1-Octen-3-yl acetate & $y=0.279 x-0.015$ & 0.995 & $2.05-8.21$ & 1.4 & 0.38 & 1.16 & SAFC & w358207 \\
\hline (+)-Camphor & $y=0.181 x-0.024$ & 0.994 & $0.99-9.85$ & 1.5 & 0.25 & 0.76 & Alfa Aesar & A10708 \\
\hline (-)-Borneol & $y=0.266 x-0.020$ & 0.998 & $0.57-9.06$ & 4.4 & 0.19 & 0.57 & Alfa Aesar & A12684 \\
\hline (-)-Terpinen-4-ol & $y=0.241 x-0.003$ & 0.997 & $0.60-9.57$ & 4.3 & 0.20 & 0.60 & Aldrich & 11584 \\
\hline Hexyl butyrate & $y=0.332 x-0.034$ & 0.991 & $4.84-7.74$ & 0.6 & 0.77 & 2.34 & SAFC & w256811 \\
\hline (+)- $\alpha$-Terpineol & $y=0.175 x-0.003$ & 0.998 & $1.02-10.23$ & 4.5 & 0.26 & 0.79 & Fluka & 83073 \\
\hline Tetradecane & Internal standard & & & & & & SAFC & 442708 \\
\hline Verbenone & $y=0.183 x-0.032$ & 0.994 & $1.30-9.88$ & 1.8 & 0.42 & 1.28 & Aldrich & 218251 \\
\hline Citronellol & $y=0.137 x-0.014$ & 0.998 & $0.90-8.69$ & 9.0 & 0.29 & 0.87 & SAFC & S60330 \\
\hline Methyl ether of carvacrol & $y=0.239 x-0.013$ & 0.999 & $0.75-9.06$ & 5.8 & 0.23 & 0.70 & Fluka & 43778 \\
\hline (-)-Linalyl acetate & $y=0.217 x-0.006$ & 0.998 & $0.72-7.18$ & 0.2 & 0.18 & 0.55 & SAFC & w263605 \\
\hline Geraniol & $y=0.338 x-0.018$ & 0.999 & $0.70-7.18$ & 3.8 & 0.22 & 0.66 & SAFC & w250716 \\
\hline Geranial & $y=0.372 x-0.022$ & 0.994 & $0.85-5.59$ & 11.7 & 0.28 & 0.85 & SAFC & w230316 \\
\hline Bornyl acetate & $y=0.317 x-0.029$ & 0.997 & $0.65-8.16$ & 5.5 & 0.20 & 0.61 & Fluka & 45855 \\
\hline Thymol & $y=0.313 x-0.029$ & 0.998 & $0.25-10.03$ & 4.8 & 0.08 & 0.25 & Sigma & T0501 \\
\hline Carvacrol & $y=1.069 x-0.118$ & 0.997 & $0.65-10.35$ & 1.3 & 0.21 & 0.65 & SAFC & w224502 \\
\hline Neryl acetate & $y=0.242 x-0.007$ & 0.999 & $0.73-7.31$ & 3.8 & 0.18 & 0.55 & SAFC & w277304 \\
\hline Geranyl acetate & $y=0.249 x-0.009$ & 0.999 & $0.46-7.42$ & 2.9 & 0.15 & 0.46 & Aldrich & 173495 \\
\hline Hexadecane & Internal standard & & & & & & Fluka & 52209 \\
\hline$(-)-(E)-\beta$-Caryophyllene & $y=0.079 x-0.002$ & 0.998 & $4.41-7.05$ & 6.6 & 0.71 & 2.16 & Sigma & 22075 \\
\hline$\alpha$-Humulene & $y=0.541 x-0.019$ & 0.999 & $0.40-6.35$ & 2.2 & 0.13 & 0.40 & Aldrich & 53675 \\
\hline (E)- $\alpha$-Bisabolene & $y=0.111 x-0.043$ & 0.999 & $1.74-6.97$ & 3.4 & 0.31 & 0.94 & Alfa Aesar & A18724 \\
\hline (-)-Caryophyllene oxide & $y=0.105 x-0.004$ & 0.999 & $2.54-10.17$ & 2.7 & 0.46 & 1.40 & SAFC & w509647 \\
\hline
\end{tabular}

Afterwards, $1 \mathrm{ml}$ of $2.8 \%(\mathrm{w} / \mathrm{v})$ trichloroacetic acid and $1 \mathrm{ml}$ of $1 \%$ $(\mathrm{w} / \mathrm{v})$ thiobarbituric acid were added to the test tube, which was boiled for $10 \mathrm{~min}$ to develop the pink coloured malonaldehydethiobarbituric acid (MDA-TBA ${ }_{2}$ ) adduct. After cooling, its absorbance was measured at $520 \mathrm{~nm}$.

\section{Nitric oxide scavenging capacity}

The nitric oxide (NO) scavenging activity of the samples was measured according to the method in the literature. ${ }^{[33]}$ In this method, $50 \mu \mathrm{l}$ of serially diluted samples were added to $50 \mu \mathrm{l}$ of $10 \mathrm{mM}$ sodium nitroprusside in phosphate-buffered saline (PBS). The reaction was carried out on a 96-well plate, incubating at room temperature for $90 \mathrm{~min}$. Finally, an equal volume of Griess reagent was added to each well, and the absorbance was read at $546 \mathrm{~nm}$.

\section{Reducing power}

Each sample $(300 \mu \mathrm{l})$ was mixed with phosphate buffer $(2.5 \mathrm{ml}$, $0.2 \mathrm{M}, \mathrm{pH} 6.6)$ and potassium ferricyanide $\mathrm{K}_{3}\left[\mathrm{Fe}(\mathrm{CN})_{6}\right](2.5 \mathrm{ml}, 1 \%$ $\mathrm{w} / \mathrm{v}) .^{[34]}$ The mixture was incubated at $50^{\circ} \mathrm{C}$ for $20 \mathrm{~min}$. Next, $2.5 \mathrm{ml}$ of $10 \%(\mathrm{w} / \mathrm{v})$ trichloroacetic acid was added to the mixture, 
which was then centrifuged for $10 \mathrm{~min}$ at $3000 \mathrm{rpm}=1000 \mathrm{~g}$. The upper layer of the solution $(2.5 \mathrm{ml})$ was mixed with distilled water $(2.5 \mathrm{ml})$ and with $0.5 \mathrm{ml}, 0.1 \%(\mathrm{w} / \mathrm{v}) \mathrm{FeCl}_{3}$, and the absorbance was measured at $700 \mathrm{~nm}$.

\section{Thiobarbituric acid reactive substances assay (TBARS)}

Egg yolk homogenate was used as lipid-rich media, ${ }^{[35]}$ i.e. an aliquot of yolk material was made up to a concentration of $10 \%$ $(\mathrm{w} / \mathrm{v})$ in $\mathrm{KCl}(1.15 \%, \mathrm{w} / \mathrm{v})$. The yolk was then homogenized for $30 \mathrm{~s}$ followed by ultrasonication for further $5 \mathrm{~min}$. Next, $500 \mu \mathrm{l}$ of the homogenate and $100 \mu \mathrm{l}$ of the sample, dissolved in methanol, were added to a test tube and made up to $1 \mathrm{ml}$ with distilled water,

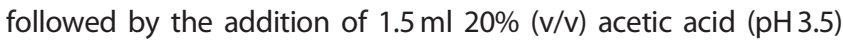
and $1.5 \mathrm{ml} 0.8 \%(\mathrm{w} / \mathrm{v})$ TBA in $1.1 \%(\mathrm{w} / \mathrm{v})$ sodium dodecyl sulfate (SDS). This mixture was stirred and heated at $95^{\circ} \mathrm{C}$ for $60 \mathrm{~min}$. After cooling at room temperature, $5 \mathrm{ml}$ of butanol were added to each tube, stirred and centrifuged at $3000 \mathrm{rpm}$ for $10 \mathrm{~min}$. The absorbance of the supernatant was measured at $532 \mathrm{~nm}$ using a spectrophotometer.

\section{Hyaluronidase inhibitory activity}

Hyaluronidase inhibition was determined by measuring the amount of $\mathrm{N}$-acetylglucosamine split from sodium hyaluronate. ${ }^{[36]}$ Next, $50 \mu$ l of bovine hyaluronidase ( 7900 units $/ \mathrm{ml}$ ) were dissolved in $0.1 \mathrm{M}$ acetate buffer ( $\mathrm{pH}$ 3.6) and then mixed with $50 \mu \mathrm{l}$ of designated concentrations of the essential oils and incubated for $20 \mathrm{~min}$ at $37^{\circ} \mathrm{C}$. Afterwards, $50 \mu \mathrm{l}$ of $12.5 \mathrm{mM}$ calcium chloride was added and incubated for 20 more minutes at $37^{\circ} \mathrm{C}$. This $\mathrm{Ca}^{2+}$ activated hyaluronidase was treated with $250 \mu \mathrm{l}$ of $1.2 \mathrm{mg} / \mathrm{ml}$ sodium hyaluronate and incubated for $40 \mathrm{~min}$ at $37^{\circ} \mathrm{C}$. After incubation, $50 \mu \mathrm{l}$ of $0.4 \mathrm{M}$ sodium hydroxide and $100 \mu \mathrm{l}$ of $0.2 \mathrm{M}$ sodium borate were added to the reaction mixture and then incubated in boiling water for $3 \mathrm{~min}$. After cooling to room temperature, $1.5 \mathrm{ml}$ of PDMAB ( $p$-dimethyl amino benzaldehyde) solution ( $4 \mathrm{~g}$ of PDMAB dissolved in $50 \mathrm{ml}$ of $10 \mathrm{~N} \mathrm{HCl}$ and $350 \mathrm{ml}$ of glacial acetic acid) were added to the reaction mixture. The absorbance was measured at $585 \mathrm{~nm}$ in a UV spectrophotometer.

\section{Statistical analysis}

All data were recorded as the mean \pm standard deviation of triplicate determinations. Each error value is magnified using the corresponding error propagation rules for arithmetic operations. Data quality was analysed by ANOVA, ${ }^{[37]}$ and means were separated using Tukey's HSD considering significant differences for $P<0.05$. Statistical analyses were conducted using SPSS Inc. (Chicago, IL, USA).

\section{Results and discussion}

The EOs were obtained by steam distillation in yields ranging from 0.2 to $1.5 \%(\mathrm{w} / \mathrm{w})$. The chemical composition of the selected EOs is shown in Table 2A for the Lavandula group and Table 2B for the Thymus group. The listing order corresponds to the elution order in a non-polar SLB5-ms column.

The main components present in the studied $L$. angustifolia oil were linalool, $\alpha$-terpineol, linalyl acetate and $(E)-\beta$-caryophyllene. Similarly, samples of plant material from Italy, ${ }^{[22,38]}$ Greece, $^{[2]}$ Bosnia-Herzegovina, ${ }^{[24]}$ Pakistan, ${ }^{[39]}$ France $^{[40]}$ and Spain ${ }^{[41]}$ show a high concentration of linalool and linalyl acetate. Just one of the studies mentioned above found $0.23 \%$ of thymol in $L$. angustifolia $\mathrm{EO}^{[39]}$ (Table 2A). Other species of the Lavandula genus also show small amounts of thymol among its components such as L. coronopofolia. ${ }^{[42]}$

In the case of $L$. latifolia oil, the main components were $\beta$-pinene, 1,8-cineole, linalool, camphor and $(E)$ - $\alpha$-bisabolene. Other samples from Spain were found in the literature, whereas 1,8-cineole, linalool and camphor were common for all the cases, $\beta$-pinene was found among the main components only in the case of Valencia ${ }^{[5]}$ and Castilla La Mancha. ${ }^{[41]}$ The high concentrations of linalool and $(E)$ - $\alpha$-bisabolene found in our sample could be a peculiarity of the growing zone. Comparatively, our sample is very similar to the ones from Zaragoza ${ }^{[43]}$ and the average of Spain. ${ }^{[44]}$

Lavandula hybrida samples show some differences between the two cultivars, 1,8-cineole, linalool, camphor, borneol, terpinen-4-ol and linalyl acetate being the main components of $L$. hybrida cV. Grosso oil. Moreover, the most abundant compounds present in L. hybrida cv. Super oil were (Z)- $\beta$-ocimene, 1,8-cineole, (E)- $\beta$ ocimene, linalool, camphor and linalyl acetate. Characteristic compounds of $L$. hybrida in the majority of samples are 1,8-cineole, linalool, camphor and linalyl acetate. Reports from Spain (Castilla La Mancha ${ }^{[41]}$ show a similar concentration of borneol to the studied sample, as well as the French report ${ }^{[45]}$ which also shows terpinen-4-ol among the main components. The report from Turkey ${ }^{[46]}$ shows ocimene like the studied samples, but the reports from Italy ${ }^{[38]}$ and Greece ${ }^{[47]}$ show different main compounds from the samples studied.

The main components of the Lavandula group were oxygenated monoterpenes, mainly alcohol (linalool), ester (linalyl acetate) and ether (1,8-cineole). Lavandula angustifolia showed the best yield in linalool production whereas both cultivars of $L$. hybrida showed the highest yields for linalyl acetate and terpinen-4-ol. The lowest yield of linalyl acetate and the highest of camphor and 1,8-cineole among the Lavandula group was found in L. latifolia. The high content of camphor found in $L$. latifolia and L. hybrida seems related to the content of sesquiterpenes of the caryophyllene type when compared with the low content of camphor shown in L. angustifolia, i.e. a high concentration of $(E)-\beta$-caryophyllene shows relation to low concentrations of camphor. ${ }^{[41,48]}$

Thymus zygis chem. thymol EO is the most studied case in the literature. In the studied sample, the main components were myrcene, $\alpha$-terpinene, $p$-cymene, $\gamma$-terpinene, linalool, thymol and carvacrol. p-Cymene was found in all reported cases. Thymol and $\gamma$-terpinene were found among the main components in all reported cases except one from Portugal ${ }^{[14]}$ and another from Almería (Spain). ${ }^{[1]}$ Portuguese reports ${ }^{[15,16]}$ are the only ones showing similar concentrations to the studied sample regarding myrcene and $\alpha$-terpinene. The report from Jaén (Spain) ${ }^{[13]}$ has a similar concentration of thymol. The studied sample is very similar to the ones from Jaén (Spain) ${ }_{r}^{[13]}$ Córdoba (Spain) ${ }^{[49]}$ Mirandela (Portugal) $^{[16]}$ and central Portugal, ${ }^{[15]}$ and similar to the ones from the north of Portugal. ${ }^{[12,50]}$

In the case of the T. hyemalis chem. cineole EO, the main compounds were $\alpha$-pinene, camphene, $\beta$-pinene, $p$-cymene, 1,8cineole, linalool, camphor, borneol, terpinen-4-ol, $\alpha$-terpineol and geraniol. $\mathrm{p}$-Cymene and borneol are present in all studied literature, whereas $\beta$-pinene, terpinen-4-ol, $\alpha$-terpineol and geraniol are just present among the main components in the studied sample. Just Spanish experimental crops samples ${ }^{[9]}$ and the studied sample show linalool as a main component of the EO. Regarding Spanish samples, the one from Almería ${ }^{[8]}$ is the most similar to 


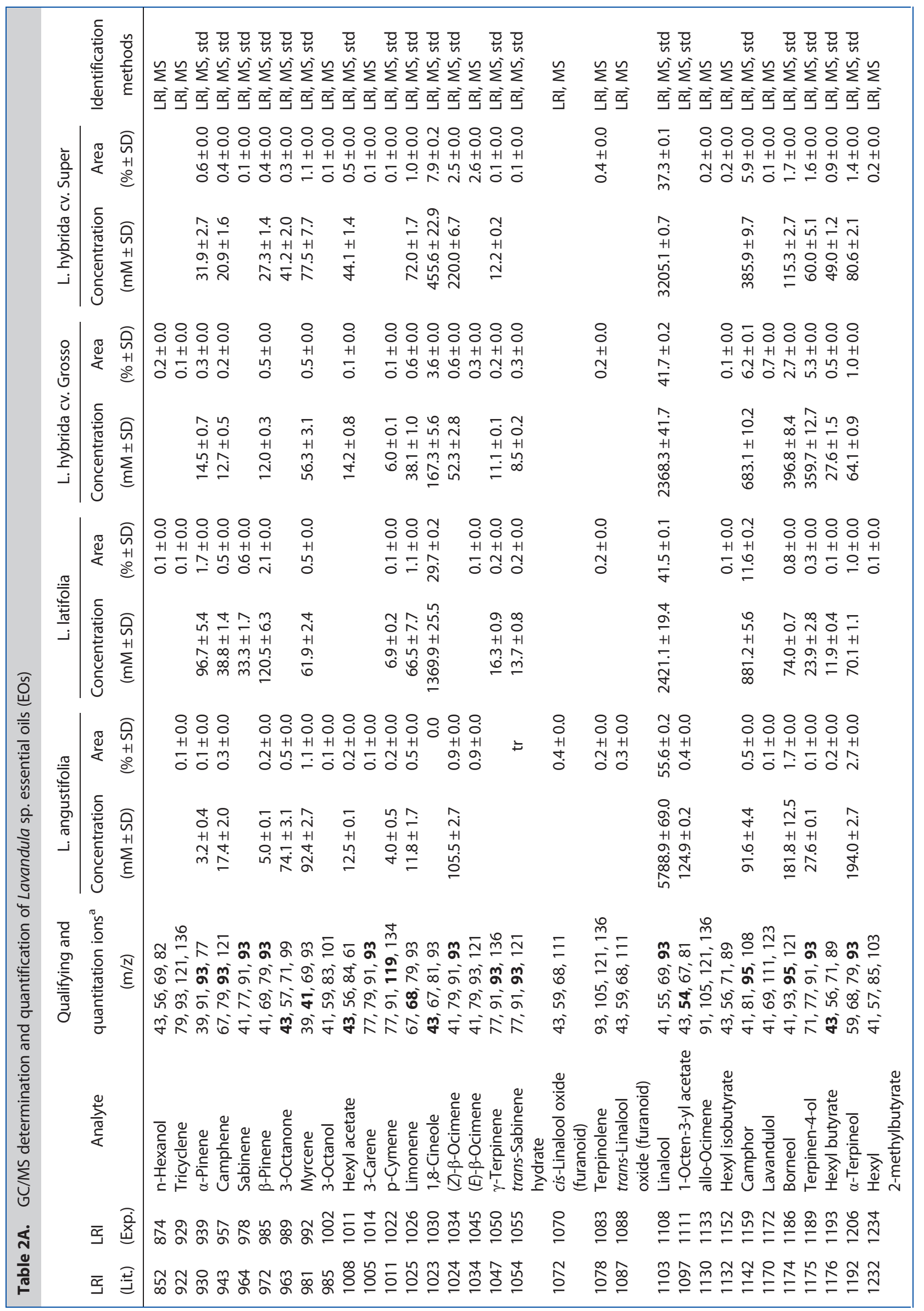




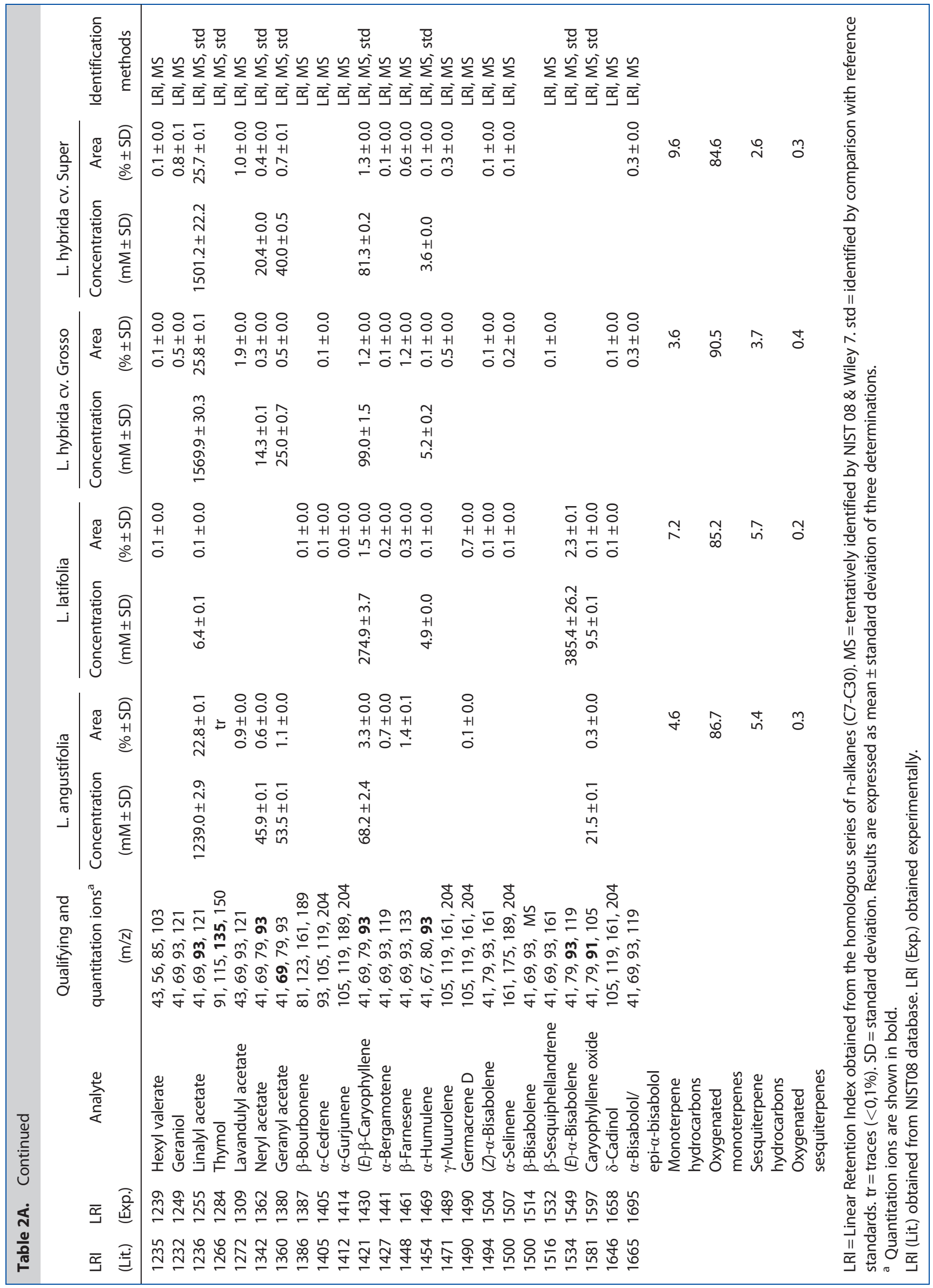




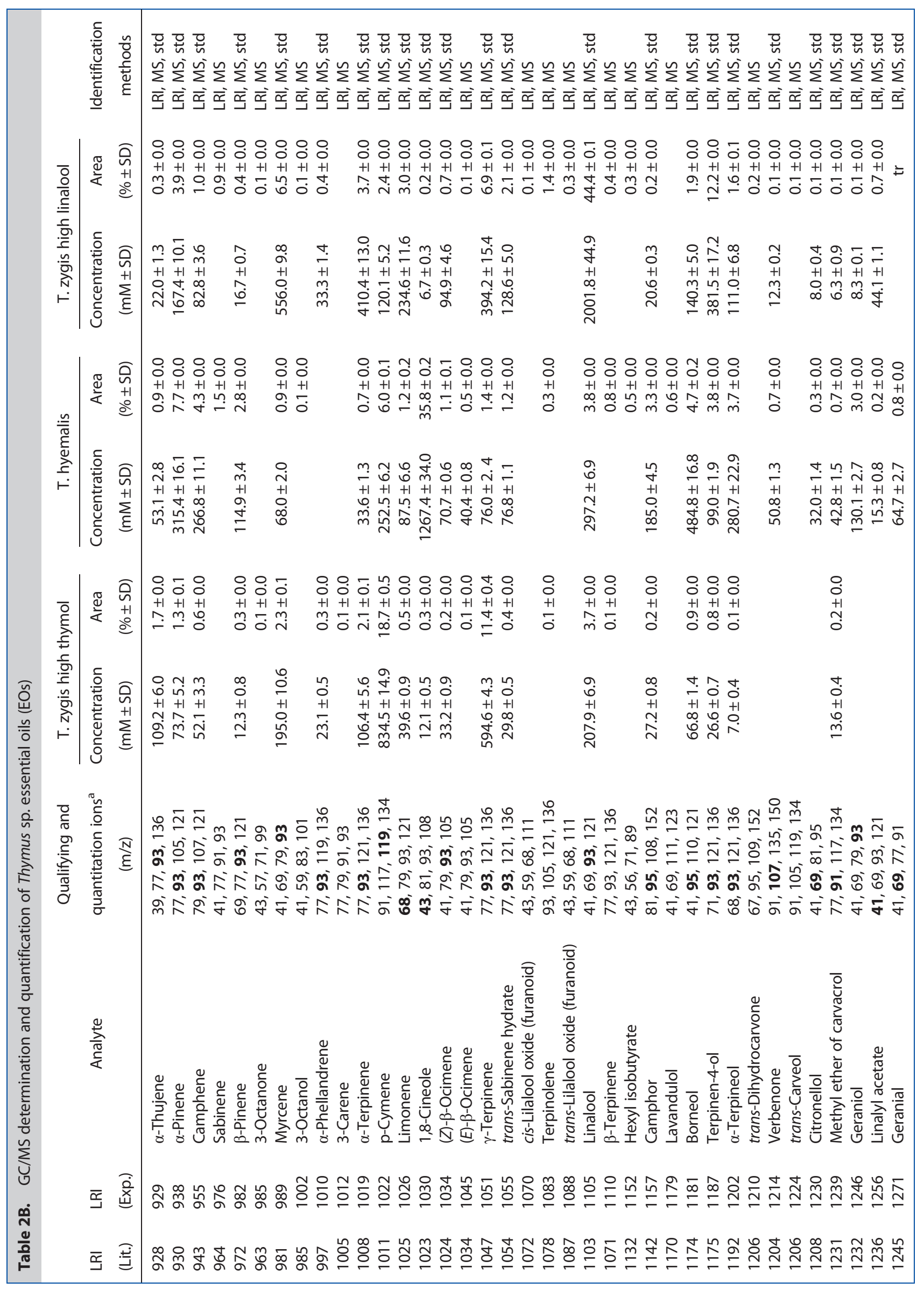




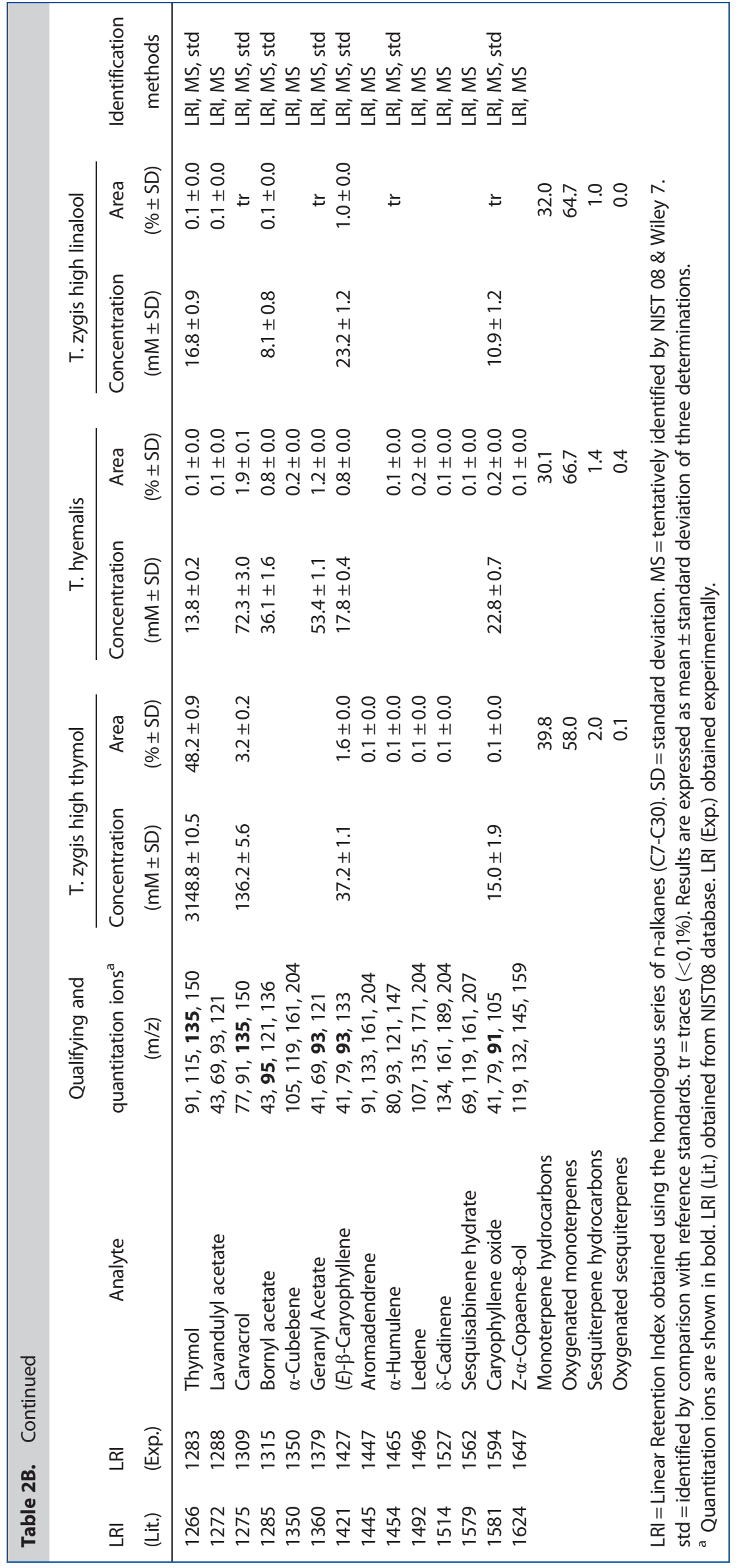




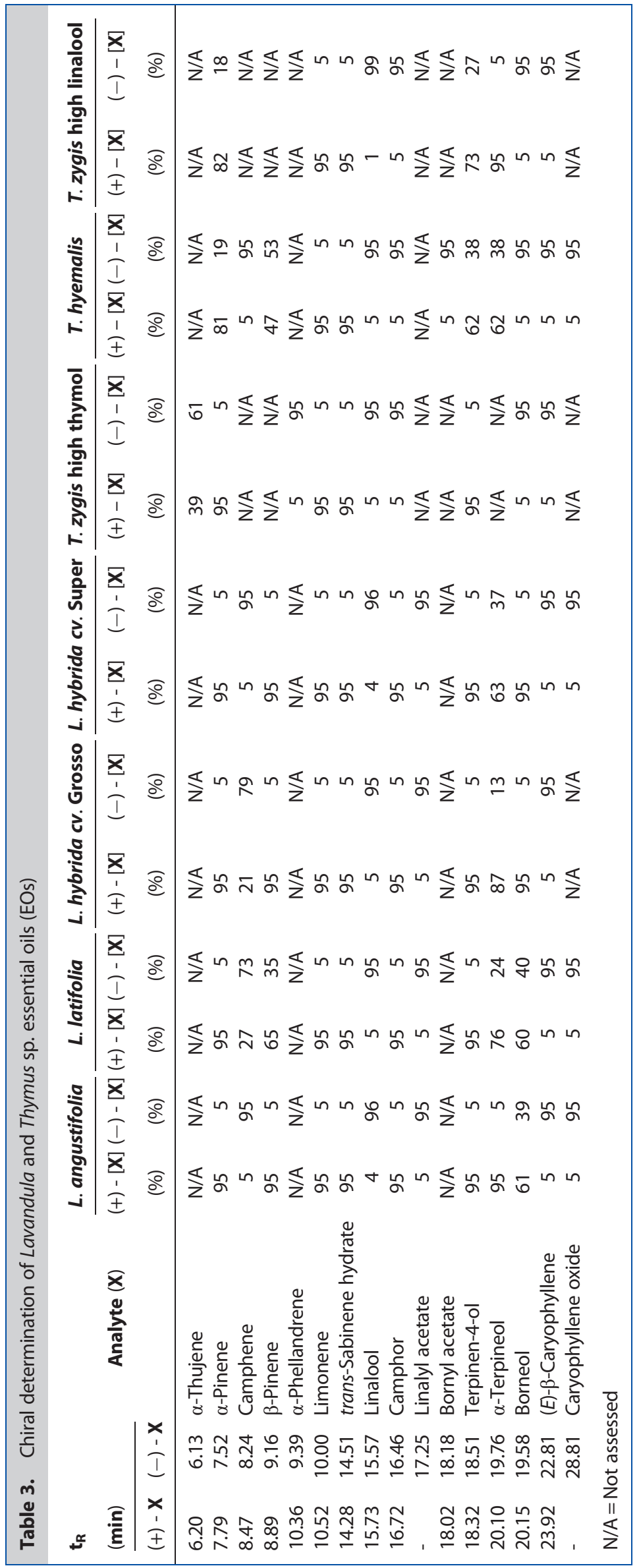


the studied sample, and the ones from designed experimental crops $^{[7,9]}$ are also similar to the studied sample. The Turkish sample ${ }^{[10]}$ is the most different sample from the ones reported here.

The main components present in T. zygis with a high proportion of linalool EO were $\alpha$-pinene, myrcene, $\alpha$-terpinene, $\mathrm{p}$-cymene, limonene, $\gamma$-terpinene, trans-sabinene hydrate, linalool and terpinen4-ol. Myrcene, $\gamma$-terpinene, linalool and terpinen-4-ol were present in most of the reported samples in the literature, establishing, thus, the main common components. A high similitude was found between the studied sample, the Spanish sample from Jaén ${ }^{[13]}$ and the experimental crops sample, ${ }^{[9]}$ a higher difference can be found in the Spanish sample from Almería ${ }^{[8]}$ and to the central Portugal sample. ${ }^{[15]}$

The main components in the case of the Thymus group (Table 2b) were oxygenated monoterpenes, mainly alcohols (thymol, linalool, terpinen-4-ol) and ether (1,8-cineole), and monoterpene hydrocarbons, $\gamma$-terpinene, $p$-cymene, $\alpha$-pinene and $\beta$-myrcene showing the highest concentrations.

Thymus zygis with a high proportion of thymol was found richer in thymol, carvacrol and their biosynthetic precursors: $\gamma$ terpinene and p-cymene. ${ }^{[51]}$ Thymus hyemalis shows a high concentration of 1,8-cineole and remarkable concentration of some of the products obtained from ad latere geranyl pyrophosphate reactions not leading to 1,8 -cineole. ${ }^{[52,53]}$ Those reactions are: geranyl pyrophosphate $\rightarrow$ geraniol $\rightarrow \alpha$-terpineol $\rightarrow$ terpinen-4-ol and geranyl pyrophosphate $\rightarrow \alpha$-pinene $\leftrightarrow \quad \beta$-pinene $\rightarrow$ camphene $\rightarrow$ camphor $\rightarrow$ borneol. T. zygis with a high proportion of linalool is rich in linalool and terpinen-4-ol, and it has an interesting concentration of $\gamma$-terpinene not further developed into p-cymene and thymol.

Regarding the chiral determination (Table 3), (R)-(-)-linalool is shown in all determinations, as reported from Turkish EOs. ${ }^{[23,54]}$ The same case happens with (R)-(-)-linalyl acetate or (S)-(+)terpinen-4-ol reported in samples from Germany. ${ }^{[21]}$ However, in the studied sample, all commercially available chiral compounds were examined, finding that (S)-(-)-camphene had lower concentration in the samples of $L$. latifolia and $L$. hybrida $\mathrm{Cv}$. Grosso among Lavandula group. Interestingly, (R)-(+)- $\beta$-pinene and (1R,2S)-(+)borneol are found in lower concentration in L. latifolia and $L$. angustifolia, respectively, $L$. hybrida being a good source of pure $(1 \mathrm{R}, 2 \mathrm{~S})-(+)$-borneol as reported in French and Swiss samples. ${ }^{[55]}$ High variation is found in (R)-(+)- $\alpha$-terpineol throughout the Lavandula group.

In the case of Thymus samples (Table 3), just two of the determined enantiomers, i.e. (S)-(+)-terpinen-4-ol and (R)-(+)- $\alpha$-terpineol, show some variation in concentration. According to the reported data from Israel, ${ }^{[55]}$ (1S,2R)-(-)-borneol has a high purity in these Thymus species. Variations were found in some worldwide studies about enantiomers of Thymus sp. EOs, ${ }^{[56]}$ in the studied samples (R)-(+)- $\alpha$-pinene and (R)-(+)-limonene were found.

Thymus zygis with a high proportion of thymol sample obtained the best results for almost all the antioxidant assays (Table 4), just three assays showed better performance for other samples, i.e. both cultivars of $L$. hybrida showed the highest chelating power, and $L$. angustifolia provided the highest $\mathrm{OH}^{\circ}$ and $\mathrm{ROO}^{\circ}$ scavenging activity.

The order of the tested samples in the reducing power assay (Figure 1) is: T. zygis high thymol $>T$. zygis high linalool $\approx T$. hyemalis $>L$. hybrida cv. Super $>L$. hybrida cv. Grosso $\approx L$. latifolia $\approx L$. angustifolia. Thymol may have the best reducing activity because it was determined as the main component of T. zygis

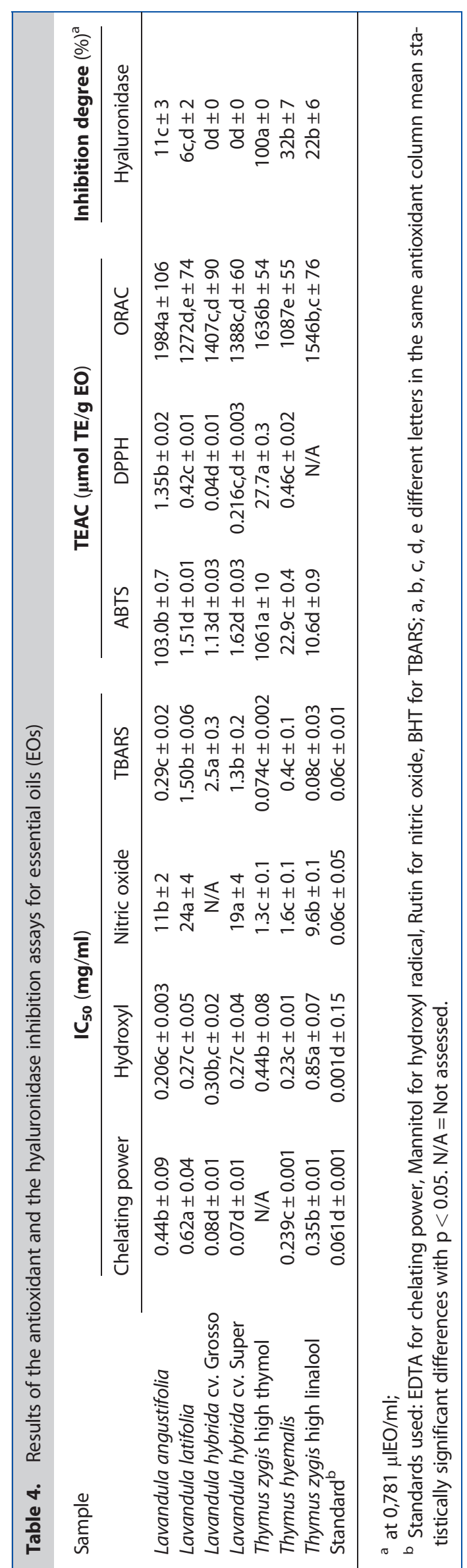




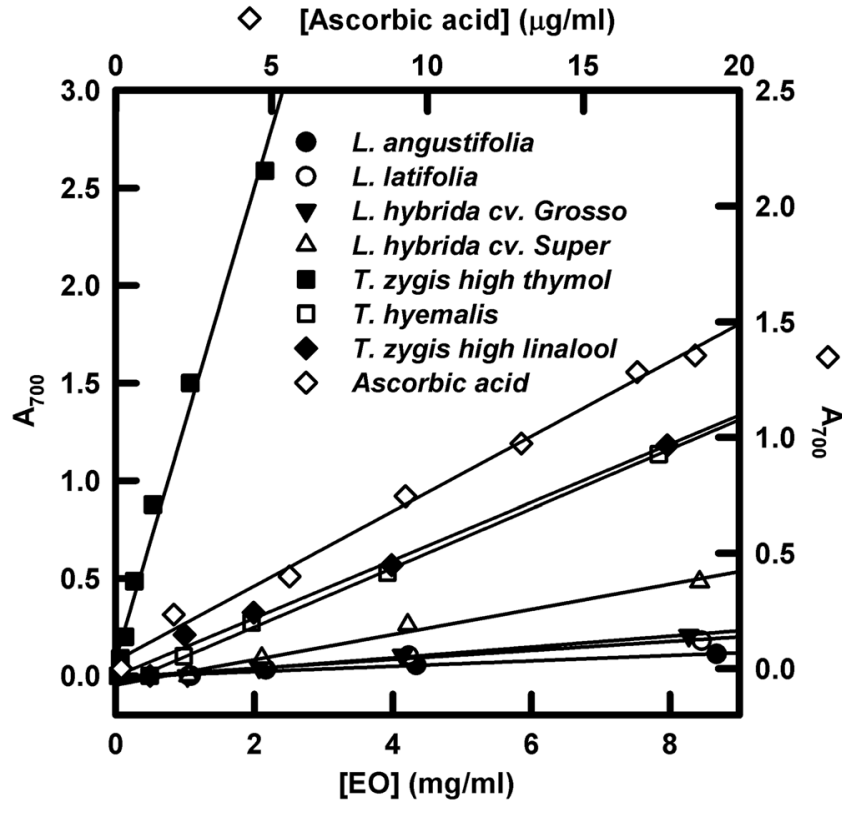

Figure 1. Reducing the power assay. Comparative for the assayed essential oils (EOs) (bottom and left axes), and ascorbic acid as standard (top and right axes)

high thymol. Positive results also agree with that reported for $T$. hyemalis from Turkey. ${ }^{[10]}$

The high performance of $L$. hybrida followed by $T$. hyemalis in chelating power (Table 4) can be explained by the high contribution of ester and ether groups to the general composition of the EOs. The case of $L$. angustifolia, showing high values in the hydroxyl and peroxyl radical scavenging assays, is explained by the high concentration of alcohol and ester groups, i.e. mainly linalool and linalyl acetate, respectively.

The results for the DPPH assay (Table 4), reveal that $L$. angustifolia has a better performance than L. hybrida cv. Super, in accordance with that reported for EOs from Italy. ${ }^{[38]}$ The best performances showed by T.zygis high thymol and T. hyemalis in some antioxidant methods (Table 4), i.e. nitric oxide, ABTS and DPPH scavenging capacity, may be as a result of the concentrations of the common molecules thymol and carvacrol existing in those two samples. The phenolic molecule thymol is the main component of T. zygis high thymol, thus, we can attribute the antioxidant activity shown in the rest of the assays to the concentration of thymol, as already reported for TBARS in EOs from Portugal. ${ }^{[14]}$ Nevertheless, in the case of TBARS (Table 4), T. zygis high linalool, not containing thymol or carvacrol, shows a low $I C_{50}$ as well as $L$. angustifolia, showing a good performance of the pair: linaloollinalyl acetate, in this test.

The good performance obtained using $T$. zygis high thymol in the hyaluronidase inhibition assay (Table 4), mainly as a result of thymol concentration (Table 2B), agreed with the reported results for Thymus sp. EOs from Japan. ${ }^{[57]}$ The relevant anti-hyaluronidase activity of EOs of T. hyemalis and T.zygis high linalool, as well as the weak inhibitory activity of $L$. angustifolia and L. latifolia EOs, could be related to their respective contents in $\alpha$-pinene, camphene and $\alpha$-terpineol (Tables $2 \mathrm{~A}, 2 \mathrm{~B}$ and 4 ).

Therefore, the EO of T. zygis with high proportion of thymol could be used as hyaluronidase inhibitor to prevent the hyaluronic acid fragmentation, which has dual effects, generation of oligosaccharides with angiogenic pro-inflammatory and immunostimulatory properties; and impairment in the reservoir capacity of ECM that holds oligoelement cations, growth factors, cytokines and several enzymes for signal transduction. Thus, the EO of T. zygis with a high proportion of thymol could aid to overcome the high number of diseases, related to the imbalance of the hyaluronic acid homeostasis. ${ }^{[25]}$

\section{Conclusions}

A sound and quantitative study of EOs of Lavandula sp. and Thymus sp. from Murcia country has been carried out. The main components of the Lavandula group were oxygenated monoterpenes, mainly alcohol (linalool), ester (linalyl acetate) and ether (1,8-cineole), whereas the main components in the case of Thymus group were oxygenated monoterpenes, mainly alcohols (thymol, linalool, terpinen-4-ol) and ether (1,8-cineole) and monoterpene hydrocarbons, with $\gamma$-terpinene, $p$-cymene, $\alpha$-pinene and $\beta$-myrcene as the most abundant.

In Lavandula sp. EOs, there are high proportions of eight (+)enantiomers, terpinen-4-ol, $\beta$-pinene, borneol and $\alpha$-terpineol among them, and five (-)-enantiomers, linalool, linalyl acetate and camphene among them, those mentioned are especially relevant for their variability or purity as commented on in the Results and Discussion section.

In Thymus sp. EOs there are high proportions of five (+)-enantiomers, $\alpha$-pinene, limonene, terpinen-4-ol and $\alpha$-terpineol among them showing variations useful for species differentiation of the samples, and 10 (-)-enantiomers borneol among them, unveiling new sources of enantiomeric pure compounds.

Linalool-linalyl acetate combination is deduced to be effective. It is found in a high concentration in Lavandula angustifolia EO, and it showed good results when tested against hydroxyl radical, peroxyl radical and azo radicals like DPPH and $\mathrm{ABTS}^{\bullet+}$.

Thymus zygis with a high proportion of thymol obtained the best results from the antioxidant assays. The phenolic molecule thymol is the main component of Thymus zygis high thymol, thus it is acceptable to attribute the antioxidant activity shown in the assays to the high concentration of thymol.

The anti-hyaluronidase activity of EOs is weak in L. angustifolia and L. latifolia, relevant in T. hyemalis and T. zygis with high proportion of linalool, and high in T. zygis with a high proportion of thymol.

The EOs of Lavandula sp. and Thymus sp., obtained from plants grown in Murcia country, have potential applications in the development of fragrances, flavours, cosmetics and drugs, they can be especially useful for the treatment of diseases related to oxidative stress, extracellular matrix breakdown and hyaluronic acid homeostasis.

\section{Acknowledgements}

This study has been partially supported by grants from the University of Murcia, Murcia, Spain [UMU-15452], [UMU-17766] and from the Fundacion Seneca, CARM, Murcia, Spain [19545/ $\mathrm{PI} / 14]$. A.B.C. has a fellowship from the Spanish government [MECD/FPU13-04013]. ${ }^{\dagger}$

${ }^{\dagger}$ Correction added on 13 November 2015, after first online publication: Acknowledgements section has been added. 


\section{References}

1. H. C. Baser, G. Buchbauer. In Handbook of Essential Oils: Science, Technology, and Applications. CRC Press: Boca Raton, FL, 2010.

2. C. N. Hassiotis, F. Ntana, D. M. Lazari, S. Poulios, K. E. Vlachonasios. Ind. Crops Prod. 2014, 62, 359.

3. G. Woronuk, Z. Demissie, M. Rheault, S. Mahmoud. Planta Med. 2011, 77, 7 .

4. C. Dobetsberger, G. Buchbauer. Flavour Fragr. J. 2011, 26, 300.

5. J. Munoz-Bertomeu, I. Arrillaga, J. Segura. Biochem. Syst. Ecol. 2007, 35, 479.

6. A. Figueiredo, J. Barroso, L. Pedro, L. Salgueiro, M. Miguel, M. Faleiro. Curr. Pharm. Des. 2008, 14, 3120.

7. M. J. Jordan, R. M. Martinez, K. L. Goodner, E. A. Baldwin, J. A. Sotomayor. Ind. Crops Prod. 2006, 24, 253.

8. F. Saez. Biochem. Syst. Ecol. 1995, 23, 431.

9. M. C. Rota, A. Herrera, R. M. Martinez, J. A. Sotomayor, M. J. Jordan. Food Control 2008, 19,681.

10. B. Tepe, C. Sarikurkcu, S. Berk, A. Alim, H. A. Akpulat. Rec. Nat. Prod. 2011, 5, 208.

11. F. Saez. Phytochemistry 1995, 40, 819.

12. M. Moldao-Martins, M. G. Bernardo-Gil, M. L. B. da Costa, M. Rouzet. Flavour Fragr. J. 1999, 14, 177.

13. C. Ballester-Costa, E. Sendra, J. Fernandez-Lopez, J. A. Perez-Alvarez, M. Viuda-Martos. Ind. Crops Prod. 2013, 50, 304.

14. S. A. Dandlen, A. S. Lima, M. D. Mendes, M. G. Miguel, M. L. Faleiro, M. J. Sousa, L. G. Pedro, J. G. Barroso, A. C. Figueiredo. Flavour Fragr. J. 2010, $25,150$.

15. M. J. Gonçalves, M. T. Cruz, C. Cavaleiro, M. C. Lopes, L. Salgueiro. Ind. Crops Prod. 2010, 32, 70.

16. C. Pina-Vaz, A. G. Rodrigues, E. Pinto, S. Costa-de-Oliveira, C. Tavares, L. Satgueiro, C. Cavaleiro, M. J. Goncalves, J. Martinez-de-Oliveira. J. Eur. Acad. Dermatol. Venereol. 2004, 18, 73.

17. S. A. Dandlen, M. G. Miguel, J. Duarte, M. L. Faleiro, M. J. Sousa, A. S. Lima, A. C. Figueiredo, J. G. Barroso, L. G. Pedro. J. Essent. Oil-Bear. Plants 2011, 14, 140.

18. M. Machado, A. M. Dinis, L. Salgueiro, C. Cavaleiro, J. B. A. Custodio. M. d. C. Sousa. Parasitol. Res. 2010, 106, 1205.

19. S. K. O'Shea, D. D. Von Riesen, L. L. Rossi. J. Chem. Educ. 2012, 89, 665.

20. C. Bicchi, E. Liberto, M. Matteodo, B. Sgorbini, L. Mondello. B. d. A. Zellner, R. Costa, P. Rubiolo. Flavour Fragr. J. 2008, 23, 382.

21. A. Mosandl. J. Chromatogr. Sci. 2004, 42, 440.

22. G. Angelo, C. Lorena, G. Marta, C. Antonella. Photochem. Photobiol. 2014, 90, 702 .

23. A. C. Aprotosoaie, M. Hăncianu, I. I. Costache, A. Miron. Flavour Fragr. J. 2014, 29, 193.

24. M. Nikolić, K. K. Jovanović, T. Marković, D. Marković, N. Gligorijević, S. Radulović, M. Soković. Ind. Crops Prod. 2014, 61, 225.

25. C. O. McAtee, J. J. Barycki, M. A. Simpson. In Hyaluronan Signaling and Turnover, vol. 123 M. A. Simpson, P. Heldin (eds). Elsevier Academic Press Inc: San Diego, CA, 2014; 1.

26. European Pharmacopoeia. Technical Guide for the elaboration of monographs, 6th ed. European directorate for the quality of medicines and healthcare, France, 2011.
27. IUPAC. Compendium of Chemical Terminology (the "Gold Book"), 2nd edn. Blackwell Scientific Publications: Oxford, 1997.

28. R. Re, N. Pellegrini, A. Proteggente, A. Pannala, M. Yang, C. Rice-Evans. Free Radic. Biol. Med. 1999, 26, 1231.

29. W. Brandwilliams, M. E. Cuvelier, C. Berset. LWT-Food Sci. Technol. 1995, 28, 25.

30. B. X. Ou, M. Hampsch-Woodill, R. L. Prior. J. Agric. Food Chem. 2001, 49, 4619.

31. M. G. Miguel, C. Cruz, L. Faleiro, M. T. F. Simoes, A. C. Figueiredo, J. G. Barroso, L. G. Pedro. Nat. Prod. Commun. 2010, 5, 319.

32. S. K. Chung, T. Osawa, S. Kawakishi. Biosci. Biotechnol. Biochem. 1997, $61,118$.

33. S. C. Ho, Y. L. Tang, S. M. Lin, Y. F. Liew. Food Chem. 2010, 119, 1102.

34. M. Oyaizu. Eiyogaku zasshi 1986, 103, 413.

35. H. J. D. Dorman, S. G. Deans, R. C. Noble, P. Surai. J. Essent. Oil Res. 1995, 7, 645 .

36. A. Sahasrabudhe, M. Deodhar. Int. J. Bot. 2010, 6, 299.

37. R. R. Sokal, F. J. Rohlf. Biometry, 4th edn. W.H. Freeman \& Co: Stony Brook University, 2012.

38. S. Maietti, D. Rossi, A. Guerrini, C. Useli, C. Romagnoli, F. Poli, R. Bruni, G. Sacchetti. Flavour Fragr. J. 2013, 28, 144.

39. A. I. Hussain, F. Anwar, P. S. Nigam, S. D. Sarker, J. E. Moore, J. R. Rao, A Mazumdar. LWT-Food Sci. Technol. 2011, 44, 1199.

40. S. Dohi, M. Terasaki, M. Makino. J. Agric. Food Chem. 2009, 57, 4313.

41. O. Santana, R. Cabrera, C. Giménez, A. González-Coloma, R. SánchezVioque, M. de los Mozos-Pascual, M. Rodríguez-Conde, I. Laserna-Ruiz, J. Usano-Alemany, D. Herraiz. Grasas Aceites (Sevilla, Spain) 2012, 63, 214.

42. T. Aburjai, M. Hudiab, V. Cavrini. J. Essent. Oil Res. 2005, 17, 49.

43. M. D. Guillén, N. Cabo. J. Sci. Food Agric. 1996, 70, 359.

44. D. Herraiz-Peñalver, M. Á. Cases, F. Varela, P. Navarrete, R. SánchezVioque, J. Usano-Alemany. Biochem. Syst. Ecol. 2013, 46, 59.

45. I. Bombarda, N. Dupuy, J.-P. Da, E. Gaydou. Anal. Chim. Acta 2008, $613,31$.

46. B. C. Andoğan, H. Baydar, S. Kaya, M. Demirci, D. Özbaşar, E. Mumcu. Arch. Pharmacal Res. 2002, 25, 860.

47. D. P. Papachristos, K. I. Karamanoli, D. C. Stamopoulos, U. Menkissoglu Spiroudi. Pest Manage. Sci. 2004, 60, 514.

48. H. Cavanagh, J. Wilkinson. Phytother. Res. 2002, 16, 301.

49. P. Penalver, B. Huerta, C. Borge, R. Astorga, R. Romero, A. Perea. APMIS 2005, 113, 1.

50. M. Moldão-Martins, G. M. Bernardo-Gil, L. M. da Costa. Eur. Food Res. Technol. 2002, 214, 207.

51. A. Poulose, R. Croteau. Arch. Biochem. Biophys. 1978, 187, 307.

52. R. Croteau, W. R. Alonso, A. E. Koepp, M. A. Johnson. Arch. Biochem. Biophys. 1994, 309, 184.

53. R. Croteau, D. M. Satterwhite, C. Wheeler, N. Felton. J. Biol. Chem. 1989, 264, 2075.

54. T. Özek, N. Tabanca, F. Demirci, D. E. Wedge, K. C. Baser. Rec. Nat. Prod. 2010, 4, 180.

55. U. Ravid, E. Putievsky, I. Katzir. Flavour Fragr. J. 1996, 11, 191.

56. E. Stahl-Biskup, F. Sáez. Thyme: the genus Thymus. CRC Press: Boca Raton, FL, 2003.

57. K. Ippoushi, Y. Yamaguchi, H. Itou, K. Azuma, H. Higashio. Food Sci. Technol. Res. 2000, 6, 74. 